\title{
O BRASIL E OS PAÍSES DO PRATA: CRUZAMENTOS CRÍTICOS E POSSIBILIDADES DO ÉPICO NO SÉCULO XIX
}

\section{BRAZIL AND THE RIVER PLATE: CRITICAL INTERSECTIONS AND POSSIBILITIES OF THE EPIC IN THE 19TH CENTURY}

Dirk Brunke ${ }^{1}$

\begin{abstract}
Resumo: No século XIX, o Brasil e o Rio da Prata assumem uma posição central quanto ao gênero épico: a polêmica sobre A Confederação dos Tamoios (1856) foi acompanhada da publicação de um amplo número de poemas, excedido apenas pela quantidade de textos publicados na região do Rio da Prata. O contato entre os dois espaços culturais tem sido explorado nos últimos anos. Os épicos brasileiros e rioplatenses se inspiraram mutuamente. Há, por exemplo, contribuições teóricas de autores rio-platenses - exilados no Brasil - que tematizam "o Brasil" nos seus textos. O exemplo mais importante neste contexto é o poema épico Cantos del peregrino (1846-57), do argentino José Mármol, que usa o motivo do "tropical" para estilizar o Brasil como espaço de inspiração, favorecendo a poesia heroica, comparando-a com as condições climáticas da Argentina, árida e carente de estímulos poéticos. Neste estudo, exploramos o contato dos épicos rio-platenses (Juan María Gutiérrez, José Mármol) e brasileiros (Joaquim Norberto Souza Silva), focando o discurso teórico e como se articula em paratextos (prólogos, notas de rodapé, glossários) e em passagens autorreflexivas nos poemas épicos.
\end{abstract}

Palavras-chave: Magalhães; A Confederação dos Tamoios; Gutiérrez; Mármol; Souza Silva; Cantos del peregrino; épica

\begin{abstract}
In the 19th century, Brazil and the River Plate countries take a leading position regarding the epic genre: the controversy over The Confederação dos Tamoios (1856) was accompanied by the publication of an enormous number of epic poems, exceeded only by the amount of texts of the same genre published in the River Plate region. The cultural intersections between the two cultural spaces has been explored only in recent years. The Brazilian and River Plate epics inspired each other. There are, for example, theoretical contributions by Argentine or Uruguay authors - exiled in Brazil - that focus on the country of exile. The most important example is the epic poem Cantos del peregrino (1846-57) by José Mármol, who uses the 'tropical' motif to put Brazil in scene as a space of inspiration that favours, above all, heroic poetry. This article explores the contact between the epics of the three countries (Juan María Gutiérrez, Joaquim Norberto de Souza Silva, José Mármol), focusing on the theoretical discourse about epic poetry in the paratexts (prologues, footnotes, glossaries) and in autoreflexive passages in epic poems.
\end{abstract}

Keywords: Magalhães; A Confederação dos Tamoios; Gutiérrez; Mármol; Souza Silva; Cantos del peregrino; epic poetry

\footnotetext{
${ }^{1}$ Ruhr-Universität Bochum - RUB, Bochum, Alemanha; https://orcid.org/0000-0003-1851-6403; dirk.brunke@rub.de
} 


\section{Relações interculturais Rio da Prata/Brasil no século XIX}

Quando o argentino Domingo Faustino Sarmiento entra, pela primeira vez, na baia de Guanabara, o espetáculo da natureza fluminense lhe causa uma febre tropical. Em seu livro autobiográfico Viajes (1845-1847), se pode ler que - vendo o Pão de Açúcar, a praia de Botafogo e o Corcovado - "facultades de sentir no alcanzan a abarcar tantas maravillas" (Sarmiento, 1886, p. 72). Mais que maravilhas, o viajante se sente ameaçado pelo sol tropical, esse "astro matador" (Sarmiento, 1886, p. 67), esse "tirano sobre cuya faz no es uno osado de echar una mirada furtiva" (Sarmiento, 1886, p. 67).

Essa imagem - estereotipada - do Brasil que o intelectual argentino mais importante do século XIX articula, não parece favorável para estimular uma onda de turismo tropical. Na primeira metade do século XIX, também não podemos caracterizar a situação política das relações rio-platense-brasileiras como propícias para o estabelecimento de relações amigáveis entre os países adjacentes. Após a independência, muitos republicanos rioplatenses, como, por exemplo, Juan Bautista Alberdi, condenaram o Brasil por manter sua forma de governo. A escravidão também foi fortemente criticada. E por último, mas não menos importante, a expansão do Brasil para o sul criou um clima antibrasileiro (Preuss, 2011, p. 35; Shumway, 1991, p. 236). No entanto, o Brasil e especialmente o Rio de Janeiro se tornam, paulatinamente, a partir dos anos 1840, um ponto de orientação espacial e ideológico para muitos românticos rioplatenses. Sobretudo, quando a ditadura de Juan Manuel de Rosas for estabelecida (1835), o Brasil, juntamente com outros países da América Latina, se tornará um "porto seguro", para o qual muitos dos românticos exilados do Prata escaparão. Alguns dos exilados até desenvolvem ideias mais lisonjeiras sobre a capital do império brasileiro, inclusive refletindo profundamente sobre a literatura da nascente nação. E, finalmente, a Tríplice Aliança atesta, mais tarde, que a relação entre os três países mudou significativamente a partir de 1850.

O contato e as relações entre os dois espaços culturais têm sido explorados nos últimos anos. Na maioria dos casos se descreve o intercâmbio de teorias políticas, comparando os dois espaços políticos (república vs. monarquia) e as diferentes dinâmicas do nation building. Além disso, a literatura gaúcha e os exilados dos países do Prata formam dois núcleos dos campos mais pesquisados (por exemplo: Chiappini 2004; Pagni, 2007; Amante, 2010; Preuss, 2011; Croce, 2016). Até hoje, além dos valiosos trabalhos de Moreira (2011; 2013; 2015; 2018), existem poucos estudos sobre o foco de interesse que exploramos nesse artigo: as relações entre os autores épicos. Fato surpreendente, considerando que no século XIX o Brasil e o Rio da Prata assumem a posição central na América Latina quanto ao gênero épico: a polêmica sobre $A$ Confederação dos Tamoios foi acompanhada da publicação de um amplo número de poemas, excedido apenas pela quantidade enorme de poemas épicos publicados na região do Rio da Prata.

A seguir, vamos destacar que, entre o Brasil e o Rio da Prata no século XIX, se desenvolveu um diálogo sobre as possibilidades e impossibilidades do gênero épico sob as condições do Romantismo e do nation building, sendo esse diálogo o primeiro exemplo de que já em meados do século XIX estava surgindo uma comunidade discursiva americana. Analisamos dois textos teóricos "Un poema brasilero. A Confederação dos Tamoios, poema por Domingo Gonçalves de Magalhães" (1857), de Juan María Gutiérrez, e "Indagações sobre a literatura argentina contemporânea" (1844), de Joaquim Norberto de Souza Silva - e um poema épico: Cantos del peregrino (1846/57), de José Mármol - para discutir a nossa tese.

\section{Ecos inter-épicos: A Confederação dos Tamoios (1856) no Rio da Prata}

É inquestionável que A Confederação dos Tamoios adquiriu posição central no discurso teórico sobre a poesia épica brasileira no século XIX. Deu-se pouca atenção à recepção do texto 
em outras regiões da América Latina, sobretudo no Rio da Prata, ainda que os textos dos épicos rio-platenses mostrem obviamente o influxo que tinha a tradição épica brasileira sobre eles. A obra do fundador da historiografia literaria uruguaia, Alejandro Magariños Cervantes (18251893), por exemplo, ostenta uma filiação com a literatura brasileira. A novela gauchesca Caramuru (1850), como o título já indica, é uma réécriture do poema homônimo de Santa Rita Durão (Burgueño, 1998). Além disso, Magariños Cervantes publica um breve estudo desse poema épico, realçando que a conquista da América oferece mais material para a poesia épica do que toda a história da Europa antiga. Ademais, caracteriza o poema épico nacional do Uruguai - Tabaré, de Juan Zorrilla de San Martín (1888) - como texto sucessor de A Confederação dos Tamoios. E as anotações que Magariños Cervantes insere no seu poema épico A cruzada argentina (1846), louvando as descrições de Magalhães da natureza americana, testemunham que o indianista brasileiro e a sua obra estão inesperadamente presentes entre os românticos ao sul do Brasil (Magariños, 1888, p. 289 e 477).

A figura mais importante quanto à presença dos épicos brasileiros no Rio da Prata e quanto ao discurso teórico sobre a poesia épica é Juan María Gutiérrez (1809-1878), fundador da historiografia literária argentina. Publica uma edição do poema épico O Uraguai, de José Basílio da Gama, e insere versos da epopeia Caramuru, de Santa Rita Durão, como epígrafes para poesias líricas (Amante, 2010, p. 518ss). E já em 1857 escreve o pequeno tratado "Un poema brasilero" sobre a A Confederação dos Tamoios, texto que será discutido em mais detalhe. Um pormenor curioso: Gonçalves de Magalhães, que "nunca se defendeu ou se pronunciou sobre sua obra" manda, desde Paris, uma carta a Gutiérrez (Magalhães, 1872), sendo essa "a única manifestação do poeta sobre sua obra" (Moreira, 2018, p. 74).

Os autores épicos do Rio da Prata, então, conhecem não só os textos épicos europeus e clássicos, modelos de toda poesia épica desde a Antiguidade. Além disso, os épicos ampliam sua visão para a produção épica no império brasileiro; no centro da discussão está Magalhães e a Confederação. Essa discussão ocorre, por um lado, por meio de paratextos como epígrafes procedimento intertextual tão estimado pelos românticos - notas de rodapé ou glossários. Além do aparato paratextual de poemas épicos, o diálogo entre os épicos se mantém, por outro lado, por meio de textos não ficcionais, articulando contribuições teóricas de forma mais explícita, sendo o tratado de Juan María Gutiérrez o que teve maior repercussão.

Juan María Gutiérrez publica "Un poema brasilero" em janeiro 1857 na revista bonaerense El Orden. Ele "toma a epopeia de seu colega brasileiro para discutir sobre a história da literatura latino-americana, apontando as diferenças de produção históricas e culturais entre uma e outra nação" (Moreira, 2015, p. 237), sendo o ponto central as diferentes condições políticas e sócio-históricas por que o "estado político do Brasil e da Argentina é (...) distinto: entre os argentinos, a ditadura de Rosas afasta os intelectuais; no Brasil, a monarquia de Pedro abre espaço para a manifestação de homens da cultura e da literatura" (Moreira, 2015, p. 231). Enquanto o Romantismo argentino se desenvolve como um movimento no exílio, sempre contra e até em confronto com o poder político, o programa romântico brasileiro se desenvolve - mais ou menos - em harmonia com a elite política, "instaurando entre el poder y [los] artistas una relación de mecenazgo a través de un sistema de favor" (Amante, 2010, p. 218). Gutiérrez entende as condições sócio-políticas do Brasil como fator imprescindível para a poesia épica. Em outras palavras: Magalhães vivia em um momento histórico em que os pré-requisitos da poesia épica eram cumpridos. Como define Gutiérrez esses pré-requisitos?

Primeira condição: afirmar a tradição épica brasileira. Em contraste com a região do Prata, o Brasil pode contar com uma tradição épica considerável e os épicos brasileiros devem se vincular a essa tradição, assim criando a nova épica romântica americana. A épica romântica, então, deve ser referenciada à literatura antes da Independência e não deverá ser uma criação ex nihili. Esse aspecto da teoria de Gutiérrez indica, implicitamente, o fato de que no Rio da Prata essa condição da poesia épica foi impossível de cumprir: não havia uma tradição épica 
rio-platense. O único poema épico da época colonial -La Argentina (1602), de Barco Centenera - só foi reeditado em 1836. O texto não passou despercebido, mas, devido ao seu tom irônicoburlesco, só poderia servir em uma extensão limitada como um texto fundamental para uma tradição da poesia épico-heróica. Será La cautiva (1837), de Echeverría, o fundador da poesia épica no Rio da Prata.

A primeira condição da poesia épica brasileira - afirmar a tradição épica - aponta à continuidade que existe entre a literatura da época colonial e a nascente literatura brasileira. Essa continuidade foi possível porque os brasileiros tinham - segunda condição da épica brasileira - uma relação afirmativa com a época colonial. Não havia, como no Rio da Prata, uma ruptura definitiva entre o período colonial e o período pós-Independência. Na Argentina e no Uruguai, a Independência marca uma ruptura definitiva e divide a história da região em duas etapas: o passado colonial espanhol e o tempo depois das guerras da Independência, início da nova época nacional. $\mathrm{O}$ início do discurso nacional sobre a identidade tinha uma posição de rechaço quanto ao tempo da "dominação espanhola". Só no decorrer do século, a partir de 1850, o discurso sobre a história e literatura nacional incluiria a época colonial. Isso significava, na primeira metade do século XIX, que o passado colonial não servia de material para poesia épica e quase sempre foi tematizado desde um ponto de vista negativo. Além da inexistência de uma tradição épica, os românticos rio-platenses da primeira metade do século não tinham material épico, extraído da história da nação, à disposição.

Embora a relação com o passado nacional seja diferente, Gutiérrez enfatiza que o "ponto comum entre elas [as duas nações, Argentina e Brasil] reside na questão colonial e na necessidade de afirmação original de seus processos" (Moreira, 2015, p. 237). Essa afirmação do tempo colonial é tão fundamental porque a constituição de uma literatura nacional só é possível se a herança do passado forma parte da literatura épica. Gutiérrez se concentra nas condições sociopolíticas que influem na poesia épica. Quando ele aponta para a continuidade entre o presente brasileiro e os tempos coloniais, enfatizando que a coexistência harmoniosa de políticos e artistas possibilitou que se constituísse e consolidasse um campo intelectual, ele realça a diferença fundamental quanto à situação em sua terra natal. Ali a relação com o período colonial é muito mais problemática e o campo intelectual só podia se formar no exílio. A diáspora dos intelectuais e a relação conflitiva com o passado nacional impossibilitam a redação de um poema épico. Em suma, Gutiérrez estiliza o Brasil como um espaço modelo para a poesia épica americana. Ele focaliza no aspecto da temática da poesia épica e favorece o passado nacional. O brasileiro Joaquim Norberto Souza Silva também teoriza o aspecto do tempo para a poesia épica nas suas "Indagações sobre a litteratura argentina contemporânea", publicadas na Minerva Brasiliense em 1844.

\section{Joaquim Norberto de Souza Silva: "Indagações sobre a literatura argentina contemporânea" (1844)}

O texto de Souza Silva - um dos intelectuais mais importante naquele momento - é o primeiro tratado teórico e historiográfico sobre a literatura no Rio da Prata, precedendo os textos do pai da historiografia literária argentina, Juan María Gutiérrez. Echeverría, que introduziu o Romantismo no Rio da Prata, comenta: "ni siquiera en nuestro país se había hecho un análisis tan serio de toda uma época de la literatura argentina" (Weinberg, 1961, p. 18). Mais significativo, o comentário de Echeverría ilustra que o tratado é o ponto de partida do diálogo entre os dois espaços culturais: Souza Silva foi motivado pelo "Certámen poético" de $1841 \mathrm{em}$ Montevidéu (Moreira, 2015, p. 231), e as "Indagações", por seu turno, foram lidas pelos rioplatenses. Uma carta de Esteban Echeverría de dezembro de 1844 testemunha que "[o] artigo publicado na Minerva teve repercussão imediata" (Moreira, 2013, p. 83). Nessa carta apela a um amigo que no momento se encontrava no Rio de Janeiro: "Procure relacionarse con el autor 
de esse artículo y estimúlele a continuar sus indagaciones. Nos conviene mucho el juicio (que no pueder ser sino imparcial) de los extranjeros" (Weinberg, 1961, p. 26). Esse amigo foi Juan María Gutiérrez, que realmente conheceu Souza Silva e forneceu-lhe bastante material novo para que ele pudesse continuar as suas "Indagações". Embora este seja o ponto de partida do diálogo entre os dois espaços culturais, Souza Silva não terminou a segunda parte das "Indagações". Mesmo assim, o encontro é crucial para o intercâmbio sobre o gênero épico entre as duas jovens nações.

Nas "Indagações", Souza Silva analisa os incontáveis cantos épicos que tematizam os acontecimentos bélicos das guerras de Independência rioplatense. Como Souza Silva escreve, "o triumpho das armas argentinas em assignaladas batalhas despertaram o enthusiasmo" (Souza Silva, 1844, p. 295) dos autores, e esses "impunharam a lyra da liberdade, [e] ergueram com seus hymnos hum monumento à independencia" (Souza Silva, 1844, p. 295). Focalizando as guerras da Independência, Silva Souza considera que essa etapa da historia rioplatense foi o solo fértil que estimulou a nascente literatura argentina. Não sem razão ele foca nesse momento histórico, porque parece muito propício para a poesia épica: batalhas e guerras, heróis que se sacrificaram e lutaram para o coletivo nacional etc. Tudo isso poderia ser o material predileto da poesia épica.

Mas Souza Silva reclama que todos os textos escritos nessa época ou que tematizam as guerras da Independência não são nada mais que composições breves e de momento e, sobretudo, escritos tendo como modelos textos europeus. Lamenta que toda a nascente literatura argentina é nada mais do que uma "cega e não estudada imitação" (Souza Silva, 1844, p. 295). Continua a crítica, tomando como exemplo o hoje desconhecido autor Esteban de Luca:

Se D. Estevan de Luca concebesse hum poema sobre as regras épicas e o desenvolvesse segundo as idéas modernas em voga, certamente que seu talento se patentearia em maior escala com mais brilhantismo, recursos que não offerece a poesia lyrica, e lhe forneceria materia em que seu genio podesse dispôr de toda a força; o enthusiasmo, porém, apenas inspirava composições ligeiras, e febricitantes, quaes meteoros que scintillam no horror das trévas e desapparecem de subito; eram obras para o momento da exaltação dos animos, e todo o seu dominio pertencia á poesia lyrica. (Souza Silva, 1844, p. 297).

É presumível que Souza Silva não use o condicional - "se patentearia" - por acaso: procura realçar que a poesia argentina da época é o produto de um momento histórico considerado como "épico" - ou seja, a matéria para a poesia épica está disponível -; mas a transformação do material épico em poesia épica ainda não se realizou. Ele lamenta o que Gutiérrez só insinuou: o fato de que o tempo da poesia épica argentina ainda não tinha chegado, o Rio da Prata ainda não tinha o seu Magalhães.

O problema central, segundo Souza Silva, é o "enthusiasmo" dos autores, produzindo nada mais do que poesia casual: "pois que, passados os momentos da febre do enthusiasmo, o seu merito intrinseco he nullo per si mesmo para entrar na analyse da critica nos momentos sosegados da leitura" (Souza Silva, 1844, p. 298). O brasileiro exclui composições breves do posível cânone da literatura nacional. Basicamente, Souza Silva contrasta a poesia lírica com a poesia épica. Enquanto a poesia lírica se baseia na afetividade e emotividade do autor - que vive num momento histórico considerado como épico ou favorável para poesia épica -, esse princípio de subjetividade não serve para estimular poesia épica. Consequentemente, a poesia épica requer uma distância (temporal e/ou emocional) entre o autor e a matéria histórica, entre o momento da criação poética e o momento histórico da diegese.

A definição dessa distancia se torna mais evidente quando Souza Silva compara a obra de Esteban Echeverría com a de Magalhães e aponta as semelhanças. Tanto Magalhães como Echeverría tematizam em seus poemas épicos o passado nacional remoto. Magalhães tematiza 
o tempo da conquista portuguêsa e Echeverría estiliza as confrontações entre os europeus e os indígenas como parte do passado nacional distante. Souza Silva teoriza o que, no início do século XX, os teóricos Lukács e Bakhtin chamariam "distância épica", segundo eles a condição fundamental para a poesia épica: significa que, entre o narrador do poema épico e o mundo da diegese épica, registra-se uma distância insuperável.

Então, para o brasileiro, em todo caso, é inquestionável que o cânone de uma literatura nacional deva incluir poesia épica e quase exige poesia épica para as jovens nações americanas. Enquanto não haja a distância (imprescindível), a realização da poesia épica parece impossível e inviável porque o passado imediato ou o tempo atual/presente não serve para a poesia épica.

Joaquim Norberto Souza Silva e Juan María Gutiérrez comparam a situação das duas literaturas nascentes e buscam um épico argentino. Buscando um épico, os dois intelectuais compartilham a ideia de que a poesia épica faz parte fundamental de uma literatura nacional e de que a história americana deve formar o acervo de material para os épicos. A história americana se torna, então, lugar de inspiração épica tanto para o brasileiro como para o argentino. Nesse sentido, o diálogo binacional sobre as possiblidades e impossibilidades da poesia épica inclui um discurso sobre as condições da épica na América em geral. Os intelectuais articulam uma "conciencia continental" (Sola, 1968, p. 69).

\section{José Mármol: Cantos del peregrino (1846-1857)}

O exilado argentino José Mármol retoma essa consciência continental, ainda que o texto que queremos analisar não seja um texto teórico, mas um poema épico: Cantos del peregrino. O poema se caracterizou como o texto mais romântico da literatura rioplatense porque realiza o programa da subjetividade romântica de forma exemplar - Mármol inscreve uma linha autobiográfica no texto, tematizando o seu exílio no Brasil (1843-1846) e as impressões diante da natureza dos trópicos - combinando-o com o apreciado motivo romântico do errante byroniano - indivíduo sem lar, sem pátria, sem amor. Esse alto grau de subjetividade vai de mãos dadas com um americanismo explícito, surpreendente para a literatura argentina do momento (Weinberg, 1997).

Assim, a passagem seguinte é apenas uma das muitas em que o herói épico expressa uma consciência de que o objetivo do canto épico não é apenas representar sua individualidade subjetiva, mas que o poema épico representa o destino coletivo dos americanos:

América es la virgen que sobre el mundo canta profetizando al mundo su hermosa libertad; [...]

No son dorados sueños de mi alma americana; son leyes que promulga para los pueblos Dios, escritas en las cosas donde la mente humana estudia y desenvuelve profética la voz. (Mármol, 1917, p. 27ss.)

Ao lado da perspectiva nacional-argentina e subjetivista-individual, o poema toma uma perspectiva geográfica e histórica mais abrangente. Esse americanismo se abre, sobretudo, entre o Rio da Prata e o Rio de Janeiro. Na baía de Guanabara, o cantor descobre "las cosas" que menciona: a natureza tropical se torna o ponto inicial de inspiração do cantor épico. Isso é significativo, porque a paisagem tropical nunca é colocada em um contexto político, muito diferente das descrições da natureza na pátria do cantor épico. Na maioria das passagens em 
que tematiza a pátria, o eu épico usa a planície árida do pampa ou o Rio da Prata (por exemplo no canto XII, p. 235ss.) para ilustrar a miséria política da Argentina. Em contraposição ao pampa politizado, a paisagem tropical da baía de Guanabara é um espaço livre de tematizações políticas em que o poeta épico, dotado de genialidade, pode se entregar a sua poesia e, segundo a citação, usar sua voz profética para expor o sublime da natureza. Nessa passagen autorreflexiva dos Cantos, o cantor épico descreve as condições da gênese do próprio poema. Implicitamente, assim como Gutiérrez e Souza Silva, o cantor também precisa de uma distância para possibilitar a poesia épica. Embora os teóricos Souza Silva e Gutiérrez definam uma distância temporal, o cantor épico de Mármol necessita uma distância espacial.

Na penúltima canção - dedicada exclusivamente ao Brasil - o eu épico recorre outra vez essa distância espacial. O narrador épico tematiza extensivamente as maravilhas da natureza e, igual a Sarmiento, o cantor de Mármol ficou deslumbrado com os trópicos e a baía de Guanabara. Depois da descrição detalhada da mata e dos montes, recorre à metáfora do "porto seguro" porque a topografia da Bahia protege a cidade contra o mar bravio tal como protege o exilado da perseguição política. A Guanabara se põe em cena como heterotopia que torna possível, como vimos, poesia épica. Mas o cantor entra num conflito com o gênero épico. Vai partir logo para a Argentina e a despolitização da terra do exílio se torna problemática.

A discrição da natureza, na penúltima canção, cobre mais de 50 estrofes e dá à canção a forma de um "himno a la desmesura de la creación" (Amante, 1998, p. 76). Culmina na exclamação do cantor: "el mundo / nada tiene más rico ni fecundo / que tú, bello y magnífico Brasil” (Mármol, 1917, p. 180). Para o eu épico é muito difícil lidar com essa desmesura, tão difícil que se vê obrigado de fazer comentários autorreflexivos sobre a estética do texto (Amante, 1998, p. 77), inserindo notas de rodapé para abrir um discurso sobre a poetologia do mesmo texto, quer dizer, a despolitização. Assim, no XII canto, insere a seguinte nota de rodapé:

A veces nos extendemos a consideraciones históricas, a otras puramente políticas y que parecen ajenas a la poesía; pero esto proviene de nuestro modo de comprender la época y la misión de sus poetas en América. [...] Los poetas americanos tienen más que nadie el deber, triste pero imperioso, de introducir con la música de sus palabras, con el corazón del pueblo, la verdad de las desgracias que éste desconoce, y el ruido de las cadenas que no siente. Además, no podríamos escribir de otro modo, porque no hay fibra de nuestro corazón que no esté herida por las espinas de nuestra época. (Mármol, 1965, p. 348ss.)

Nesse comentário, o autor articula uma escusa para introduzir a política contemporânea no discurso épico. A desmesura da paisagem tropical, então, se transpõe à criação poética, de tal maneira, que a criação mesma transgride os limites do gênero épico (Amante, 1998, p. 77). O autor, Mármol, por assim dizer, está lutando com o gênero épico, porque a escolha da matéria - política atual - ultrapassa o limite da poesia épica. O poema épico do argentino Mármol é, então, outra contribuição ao discurso sobre as possibilidades da poesia épica no século XIX. Também para Mármol, a questão da escolha da matéria está no centro da discussão. Seu tom de desculpas revela uma forte consciência estética e uma consciência de que a situação da poesia épica sob as condições do Romantismo se torna mais complexa.

\section{Conclusão}

Os textos analisados mostram que os românticos - além da perspectiva nacional, tão fundamental para o Romantismo - também nutrem interesse por questões transfronteiriças e americanas, principalmente no que se refere ao gênero da epopeia e suas possibilidades na América. Os autores apresentados têm uma ideia compartilhada de quais gêneros devem fazer parte da literatura nacional emergente, de que o épico deve dar sua contribuição. É curioso que 
não sejam apresentadas questões sobre a forma (versificação, estrófica, métrica, rima etc.). Em vez disso, todos os autores se concentram na questão da matéria, segundo a qual o passado distante nacional deve ser usado como material privilegiado da poesia épica. Desenvolve-se um discurso teórico sobre as possibilidades e impossibilidades da poesia épica americana.

Se forem, por um lado, abertas perspectivas comparativas que abranjam o Rio da Prata e a baía de Guanabara - para discutir a literatura nacional emergente e o papel desempenhado pelo épico - e se , por outro lado, a literatura de um país for usada para descrever a outra literatura, isso ilustra o surgimento precoce de uma perspectiva latino-americana da literatura e do gênero épico.

\section{REFERÊNCIAS}

AMANTE, Adriana. Poéticas y políticos del destierro. Argentinos en el Brasil en la época de Rosas. Buenos Aires: Fondo de Cultura Económica, 2010.

AMANTE, Adriana. Las huellas del peregrino. El exilio en el Brasil en la época de Rosas. In: IGLESIAS, Cristina, org. Letras y divisas. Ensayos sobre literatura y rosismo. Buenos Aires: Eudeba, 1998. p. 69-90.

BURGUEÑO, María. O Caramuru y Caramurú: sus relaciones en la formación de un protoimaginario nacional uruguayo. Revista Iberoamericana, Pittsburgh, v. 64, n. 182-183, 1998. p. 117-128.

CHIAPPINI, Ligia; MARTINS, Maria Helena; PESAVENTO, Sandra, orgs. Pampa e Cultura: de Fierro a Netto. Porto Alegre: Universidade Federal do Rio Grande do Sul, 2004.

CROCE, Marcela, org. Historia comparada de la literatura argentina y brasileña. V.1. I: De la colonia a la organización nacional (1808-1845). Córdoba: Villa María, 2016.

GUTIÉRREZ, Juan María. Un poema brasilero. A Confederação dos Tamoios, poema por Domingo Gonçalves de Magalhães. In: LAMAS, Andrés; FIDEL LÓPEZ, Vicente; GUTIÉRREZ, Juan María, orgs. Revista del Río de la Plata. Periódico Mensual de Historia y Literatura de América, v. III, n. 12, Buenos Aires: Casavalle, 1872 [1857]. p. 481-518.

MAGALHÃES, Domingo Gonçalves de. Carta del señor Magalháes. In: LAMAS, Andrés; FIDEL LÓPEZ, Vicente; GUTIÉRREZ, Juan María, orgs. Revista del Río de la Plata. Periódico Mensual de Historia y Literatura de América, v. III, n. 12, Buenos Aires: Casavalle, 1872. p. 518-520.

MAGARIÑOS CERVANTES, Alejandro. Tabaré. In: MAGARIÑOS CERVANTES, Alejandro. Palmas y ombúes. Montevideo: Becchi, 1888. p. 477-480.

MÁRMOL, José. Cantos del peregrino. Con una introducción de Juan María Gutiérrez. Buenos Aires: Cultura Argentina, 1917.

MÁRMOL, José. Cantos del peregrino. Org. Elvira Burlando de Meyer. Buenos Aires: Eudeba, 1965.

MOREIRA, Maria Eunice. Sob a égide do nacionalismo: relações literárias entre Brasil e Argentina no século XIX. Ciências \& Letras, Porto Alegre, n. 49, 2011, p. 111-120. 
MOREIRA, Maria Eunice. Juan María Gutiérrez e D. J. Gonçalves de Magalhães: um crítico argentino e um poema brasileiro. Cuadernos del CILHA, Mendoza, v. 19, n. 29, 2018, p. 6775 .

MOREIRA, Maria Eunice. Literatos argentinos e brasileiros no império de Pedro II: algumas anotações. Historiae, Rio Grande, v. 6, n. 1, 2015, p. 228-244.

MOREIRA, Maria Eunice. Hermanos e irmãos: As relações literárias entre os românticos argentinos e brasileiros durante o Romantismo. Teresa. Revista de Literatura Brasileira, São Paulo, n. 12-13, 2013, p. 79-93.

PREUSS, Ori. Bridging the Island: Brazilians' Views of Spanish America and Themselves, 1865-1912. Madrid; Frankfurt: Iberoamericana / Vervuert, 2011.

PAGNI, Andrea. Imaginar el Brasil desde el Río de la Plata: Mediaciones, desplazamientos y contrastes en los relatos de viaje durante la primera mitad del siglo XIX. In: SEDYCIAS, João, org. Brasil en el imaginario literario hispanoamericano / A América Hispânica no imaginário literário brasileiro. Pernambuco: Editoria Universitária UFPE, 2007. p. 81-97.

SARMIENTO, Domingo Faustino. Viajes por Europa, Africa y América 1845-47. Santiago de Chile: Imprenta Gutenberg, 1886.

SHUMWAY, Nicolas. The invention of Argentina. Berkeley: UoCP, 1991.

SOLA, Graciela de. Los Cantos del peregrino de José Mármol. Comentario, v. 60, 1968, p. 64-71.

SOUZA SILVA, Joaquim Norberto de. Indagações sobre a litteratura argentina contemporânea. Minerva Brasiliense, Rio de Janeiro, v. 10, n. 1, 15.03.1844, p. 294-301.

WEINBERG, Félix. Repercusión crítica de los Cantos del peregrino de Mármol. In: BARBA, Fernando E.; MAYO, Carlos A., orgs. Argentina y Chile en la época de Rosas y Portales. La Plata: Editorial de la Universidad Nacional de la Plata, 1997. p. 35-49.

WEINBERG, Félix. La literatura argentina por un crítico brasileño en 1844. Rosario: Universidad Nacional del Litoral, 1961.

Dirk Brunke - Doutor em Letras, é pós-doutorando na Ruhr-Universität Bochum, onde leciona. É autor de Das romantische Epos am Río de la Plata. Subjektivität und Lyrisierung (2018) e organizador de El yo en la epopeya. Nuevos espacios de subjetividad en la poesía épica ibérica y latinoamericana del siglo XIX (2019), entre outras publicações. É membro da equipe de pesquisadores do projeto Discurso da épica nas culturas lusófonas do século XIX - Probral Capes/DAAD 2018-2021. Orcid: https://orcid.org/0000-0003-1851-6403.

Submetido em 10/01/2020

Aceito em 20/03/2020 